\title{
EFFECT OF STRATEGIC DETERMINANTS OF TRAINING ON THE JOB PERFORMANCE, EFFECTIVENESS AND EFFICIENCY: AN EMPIRICAL STUDY
}

\author{
A.K.M. MOMINUL HAQUE TALUKDER \\ JASHIM UDDIN AHMED \\ School of Business \\ North South University Dhaka 1229, Bangladesh
}

\begin{abstract}
Investments in the development of human capital, which are concerned with the development of knowledge, competencies and qualifications of employees, are considered more important today for the performance of an organization and for the economic growth of a country than investments in physical capital. Keeping this in perspective, this research examined the effect of the determinants of training such as training and development, strategic objective, culture and value, knowledge and skills, rewards and promotion, readiness and flexibility on job performance, effectiveness, and efficiency of employees in a large service conglomerate. The results indicated significant positive relationship of training and development, strategic objectives, culture and values, knowledge and skills, rewards and promotion with job performance, effectiveness, and efficiency of employees. The study also reported the importance of training, strategic objective, culture and value, knowledge and skills, rewards and promotion to augment job performance, effectiveness and efficiency but undermined the significance of readiness and flexibility. The employees underpin motivational factors that are responsible for better job performance. The findings suggest that harnessing all these determinants may render service organizations with the potential to foster job performance, effectiveness, and efficiency of employees.
\end{abstract}

Keywords: Training, Rewards, Performance, Effectiveness.

\section{Introduction}

Employee training is at the heart of modern management practice in any organization (Purcell, 2000). From a management point of view, training programmes are expected to provide numerous benefits to the organization including employee development, increased productivity and improved employee performance (Watson, 2008). Training and employee development are vital contributors to organizational success and will continue to be so in the foreseeable future. Changes in economic forces and globalization point to the importance of human resources and skilled "knowledge workers" as key sources of sustainable competitive advantage (Drucker, 1999). Every indication is that the need for training will continue given increasing demands on organizations to boost productivity, keep pace with technological advances, meet competitive pressures, use 
team-based decision-making and problemsolving, reengineer processes, and satisfy employee development and retention requirements.

With this emphasis on learning and skill development, employers hope expenditures will yield a favourable return on their investment. Studies suggest that many training and development activities are implemented on blind faith in the hope that they will produce results (Arthur et al., 2003). One study found that employers who were in the top quartile of their peers relative to the average training expenditure per employee experienced 24 per cent highergross profit margins, 218 per cent higher income generation per employee, and a 26 per cent higher price-to-book value of company stock price relative to those employers in the bottom quartile (Wells, 2001).

\section{Objective of the Study}

- The present study is aimed at examining the effect of various determinants of training on job performance, effectiveness and efficiency of employees especially in a multinational company's (MNCs) service firm operating in Bangladesh. It is also rational to say something about the training and development landscape in Bangladesh. With regard to training in public entities, the Bangladesh Public Administration Training Centre (BPATC) conducts most of the training and development activities for all officers employed in ministries, departments and directorates to make them aware of government policies, familiarize them with government rules and regulations and keep them up-to-date with contemporary issues of public administration and management (BPATC, 2009). The Asian Development Bank (ADB) study pointed out that fewer than 5 per cent of the employees in the private sector receive formal employer-sponsored training either in the workplace or offsite (ADB, 2007). Considering the pressing for training and development, the present study attempts to determine the effect of training in a multinational company operating in Bangladesh and the determinants influencing employee's performance, effectiveness and efficiency. Though a number of studies have been conducted in different developed countries related to training none of them (Smith \& Dowling, 2001; Saks \& Belcourt, 2006; Kurosawa, 2001) empirically looked into the impact of training on job performance, effectiveness and efficiency in a local context and more specifically in Bangladesh. The present study will shed light to determine the determinants of training contributing to job performance, effectiveness and efficiency of employees in the organization. This will be one of the premier empirical studies to explore the effect of training on job performance, effectiveness and efficiency of employees within a large MNCs' service organization.

\section{Literature Review}

Employee Training and Development is aimed at improving individual, team and organizational effectiveness (Kraiger \& Ford, 2007) and is regarded as one of the most widespread human resources (HR) practices (Boselie et al., 2005). To remain competitive in the new economy and the rapidly changing environment, corporations and even small businesses need to keep employees working at the top of their games once they are hired and this has to be done by formal training (Morin \& Renaud, 2004). In contrast, job performance which is one of the variables of the study is defined as an 
aspect of the work behaviour domain that is of relevance to job and organizational success (Austin et al., 1991). It represents a sample of the universal behaviours an individual performs in the course of work that is relevant to judging success. It is a key construct in human resource management because the criteria for promotion as well as for selection validation purposes are frequently drawn from the job performance domain. Job performance is a commonly used, yet poorly defined concept, in industrial and organizational psychology-the branch of psychology that deals with the workplace. It most commonly refers to whether a person performs his/her job well. Performance is an extremely important criterion that relates to organizational outcomes and success. From a psychological perspective, Campbell describes job performance as an individual level variable. That is, performance is something a single person does.

The American Society for Training and Development estimates that U.S. organizations spend almost $\$ 110$ billion on employeelearning and development annually, with an average expenditure of more than $\$ 1,400$ per employee (Rivera \& Paradise, 2006). Performance is a function of several factors, but perhaps it can be boiled down to three primary concerns: ability, motivation, and environment. Each individual has a unique pattern of strengths and weaknesses that play a part. But talented employees with low motivation are not likely to succeed because motivation affects willingness to learn (Kraiger \& Ford, 2007). In addition, other factors in the work environment or even in the external environment, which includes personal, family, and community concerns, can impact performance either positively or negatively. If an employee's performance is not up to standards, the cause could be either a skill problem (knowledge, abilities, technical competencies), an effort problem (motivation to get the job done), and/or some problem in the external conditions of work (e.g. poor economic conditions, supply shortages, difficult sales territories). Any of these problem areas could cause performance to suffer (Scott \& Kenneth, 1985). Although there are many determinants that might trigger training and subsequently job performance, the present study has considered only five variables including training and development, strategic objectives culture and values, knowledge and skills, rewards and promotions, and readiness and flexibility and assumed that these are part and parcel of training initiatives which would affect job performance, effectiveness and efficiency in the organization.

\section{Training and Development (TAD)}

Training can be defined as the systematic acquisition of knowledge, skills and attitudes that together lead to improved performance in a specific environment (Salas et al., 2006). It is also defined by Patrick (2000) as a systematic development of the knowledge, skills, and expertise required by a person to effectively perform a given task or job. Landy (1985) defined job training as "a set of planned activities on the part of an organization to increase the job knowledge and skills or to modify the attitudes and social behaviour of its members in ways consistent with the goals of the organization and the requirements of the job". Conversely, employee training and development is regarded as one of the most widespread human resources practices (Boselie et al., 2005). As the overall focus of TAD is on improving employee performance (Kraiger et al., 2004), a central issue is whether there is a direct relationship between TAD and employee outcomes. 
Employees who perceive that they are not being provided with sufficient training opportunities might develop higher turnover intentions (Pfeffer \& Sutton, 2006). Based on arguments from the social exchange theory (Shore et al., 2006), employees who perceive that their employer provides sufficient and relevant training opportunities might be more reluctant to leave their employer, as they feel obliged to reciprocate the offer provided (Benson et al., 2004). There is an increasing awareness in organizations that the investment in training could improve organizational performance in terms of increased sales and productivity; enhanced quality and market share; reduced turnover, absence and conflict (Huselid, 1995). The knowledge and skills that workers acquire through training have become important in the face of the increasing rapid changes in technology, products, and systems. Most organizations invest in training because they believe that higher performance will result (Kozlowski et al., 2000). From the above, it can be hypothesized that:

H1: Training and development will be positively related to job performance, effectiveness and efficiency of employees in the organization.

\section{Strategic Objective, Culture and Value} (SOCV)

The term "strategic objectives" refers to an organization's articulated aims or responses to address major changes or improvements, competitiveness or social issues, and business advantages. Strategic objectives generally are focused both externally and internally and relate to significant customer, market, product, or technological opportunities and challenges (strategic challenges). Broadly stated, they are what an organization must achieve to remain or become competitive and ensure long-term sustainability. Strategic objectives set an organization's longer-term directions and guide resource allocations and redistributions. Organizational culture, which refers to a system of shared meanings and manifestations of organizational behaviour (Kopelman et al., 1990), is critical to all forms of organizational activity, as it represents a core set of values governing the attitudes, interactions and behaviours employees adopt towards their work environment and, consequently, their decision regarding training. On the other hand, values are central to understanding the meaning that people place on work (Nord, Brief, Atieh, \& Doherty, 1990) and the degree of satisfaction that they find when they 'fit' in a given work environment.

Strategic objective, culture and value regarding training and development sets objectives, demands a yardstick to measure the fulfillment of the objectives of training programmes. If that training objective lacks specificity or measurability, it is not very useful for an organization, simply because there is no way of determining whether it is helping the organization to move toward the organization's mission and vision. Most of the strategic objectives are directed toward generating greater profits and returns for the owners of the business, others are directed at customers or society at large (Simone, 2010). According to Smith (2009), culture is what naturally emerges as individuals transform themselves into social groups as tribes, communities, and ultimately, nations. In other words, culture is comprised of distinct observable forms that groups of people create through social interaction and use to confront the broader social environment. This second view of culture is most relevant to the analysis and evaluation of organizational culture and to cultural 
change strategies that leaders can employ to improve organizational performance. From the above, it can be hypothesized that:

H2: Strategic objective, culture and value related to training and development will be positively related to job performance, effectiveness and efficiency of employees in the organization.

\section{Knowledge and Skills (KS)}

Knowledge is what a person knows that is relevant to the job (e.g. knowledge of legal procedures for a police officer). Skill refers to a person's current level of performance on a particular task or family of tasks. Skills can be classified as either mental (e.g. report writing) or physical (e.g. dragging heavy weight) although most job tasks involve elements of both. Skill reflects a person's current level of performance. Skills can be assessed by a variety of devices, including Assessment Centres, psychological tests, and work samples. Training has been linked to higher profits in firms (Hambledon Group Ltd., 2000) and skill differentials form an enduring aspect of national differences in productivity (Broadberry \& O’Mahony, 2004). The role of skills is particularly significant. Although it is generally asserted that the way to achieve high profits and high performance organizationally is through high skills competition and a high skills economy (Brown, 2001), in practice, many firms can and do compete on the basis of cost (Bach, 2005). Nor does switching to high-skills competition necessarily result in high-skills labour. As Hannon's (2005) research reveals, moving to knowledgeintensive competitions has a variable, rather than a positive, impact on workers' skills.

Smith and Sadler-Smith (2006) reported knowledge-workers as those who not only acquire knowledge, but also who understand the importance of sharing that knowledge across the organization, thereby emphasizing network, relationships and trust. The important factor is how far they are recognized as critical to the organization, and how far their knowledge-sharing is promoted by the organization rather than being viewed as 'time-wasting'. Because knowledge workers become the central plank of the labour process, HRM takes up a critical role in appointing, retaining and harnessing their skills to the full (Purcell et al., 2003). From the above, it can be hypothesized that:

H3: Knowledge and skills related to training and development will be positively related to job performance, effectiveness and efficiency of employees in the organization.

\section{Rewards and Promotion (RP)}

Achieving and sustaining competitive advantage necessitates that organizations leverage human capital in a desired direction (Boxall \& Purcell, 2003). The principle means by which this is accomplished is through the incentive power of rewards (Lawler, 2000). Viewed through the lens of the agency theory, various types of rewards can be used by an employer to direct employee behaviours and align employee-employer interests (Eisenhardt, 1989). The expectancy view also suggests that motivation increases when a behaviour is highly instrumental to achieving valent outcomes (Porter \& Lawler, 1968). Incentiveoriented rewards, for instance, are widely used to support competitive strategies, such as innovation, quality, and customer focus (Allen \& Kilmann, 2001). Organizationally, promotions serve the critical role of ensuring the optimal allocation and utilization of human resources (Kaplan \& Ferris, 2001). 
Promotions represent opportunities for coalitions to maintain or wrest control of key organizational positions.

In recent years there has been a growing emphasis in the literature that reward should be utilized as a strategic tool to manage corporate performance and to influence corporate values and beliefs (Lewis, 2006). An effective compensation and reward philosophy takes into account the dynamic nature of the organization's change initiatives (Flannery, Hofrichter, \& Platten, 1996) while allowing the firm to establish and navigate - its ultimate course (Condrey, McCoy, \& Fleury, 2006). Reward programmes that help organizations achieve specific change goals such as greater creativity, innovative products, competitiveness, collaboration and teamwork, employee commitment and loyalty, long-term plans, and continual learning and application of new skills are positively related to organizational goal achievement (Ulrich, Zenger, \& Smallwood, 1999). From the above, it can be hypothesized that:

H4: Rewards and promotions related to training and development will be positively related to job performance, effectiveness and efficiency of employees in the organization.

\section{Readiness and Flexibility $(R F)$}

Before trainees can benefit from any form of training, they must be ready to learn (Goldstein, 1986). Trainee readiness refers to both the maturational and experiential factors that a learner brings to the training programme. Readiness, though, is typically seen as primarily due to the number and kind of previously learned intellectual skills (Gagne, 1985). To examine readiness, the capabilities of the trainees must be investigated in the context of the ability requirements of the training programme content (Fleishman \& Mumford, 1989). If there is a mismatch between the ability requirements of the training programme and the training capabilities of the trainee, the training programme will fail.

Readiness to learn is how a group comes to recognize that stimuli for learning are occurring and that the group needs to change, learn something in order to accomplish its work, and to actually make a decision to take action (Sessa \& London, 2006). Groups are more likely to be ready to learn when they have appropriate boundary permeability and when they are sensitive to the demand and concerns of other individuals and as they grow in maturity. As groups mature, they appreciate teamwork, welcome individual expression, and engage in experimentation and collaboration (Kasl et al., 1997). Readiness is the maturity and experience factors in a trainee's background. Recognizing individual differences in readiness is as important in organizational training as it is in any other teaching situation. The receptiveness and readiness of participants in training programmes can be increased by having them complete questionnaires about what they are attending training for and what they hope to accomplish. However, managers can undertake six strategies (Bohlander \& Snell, 2004) such as using positive reinforcement, eliminating threat and punishment, being flexible, having participants set personal goals, designing interesting instructions, and breaking down physical and psychological obstacles to upkeep the training environment conducive for learning. In addition, it promotes diversity, cross-training, and has a positive impact on workplace culture, morale and employee recruitment, engagement and retention (Whetten \& Cameron, 2007). From the above, it can be hypothesized that: 
H5: Readiness and flexibility related to training and development will be positively related to job performance, effectiveness and efficiency of employees in the organization.

\section{Conceptual Model}

The main leverage for developing the human capital of an organization resides in the training of its employees. It is considered one of the most effective methods for increasing employee productivity (Barrett \& O'Connell,
2001), communicating organizational objectives to new employees (Arthur et al., 2003), retaining the best performing employees (Bassi \& McMurrer, 2008) and managing the market and business changes (Rothwell \& Kolb, 1999). Nevertheless, organizations often hesitate before investing resources in the training and development of their employees. This situation is partly due to the difficulty associated with evaluating the impact of this investment on organizational and economic results (Bouteiller \& Cossette, 2007).

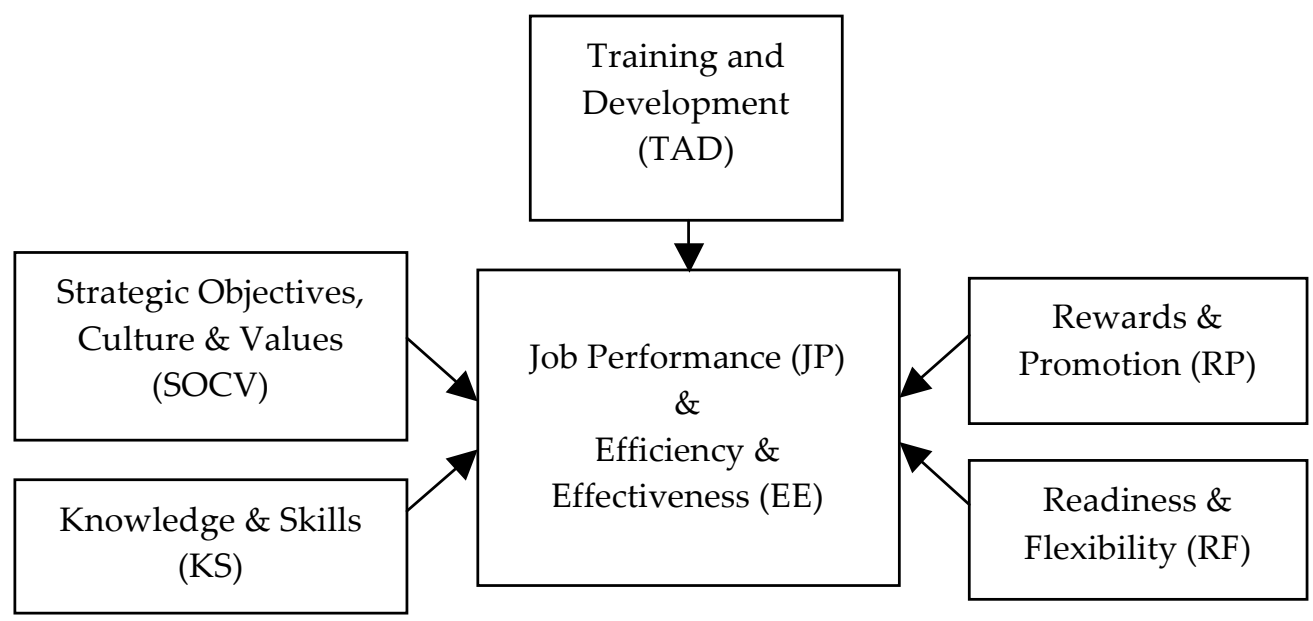

Figure 1. Hypothesized model of the study.

Most research studies have an explicit or implicit theory, which describes, explains, predicts or controls the phenomenon under study. Theories are linked to conceptual modelsandframeworks; whereas aconceptual model is more abstract than a theory and a theory may be derived from a model; the framework is derived deductively from the theory (Burns \& Groves, 2001). The present study tested a model (Figure 1) that stemmed from a review of the literature by integrating theory and research questions pertaining to training and development, strategic objectives, culture and values, knowledge and skills, rewards and promotions, readiness and flexibility and their relationship with job performance, effectiveness and efficiency in the organization. The study also assumed 
Stevens (1996) to frame an instrument and subsequently to obtain data in a quantitative study there has to be around 20 respondents for each variable and this also supports statistical power to the research. In the study, the effective sample size was 100 and this consisted of 5 independent variables in addition to 2 dependent variables, each having 5 items to see to what extent these items accounted for the dependent variables. Hence, the instrument can be justified. The dependent variables were job performance, efficiency and effectiveness, and the independent variables were training and development, rewards and promotions, readiness and flexibility, knowledge and skills and strategic objectives, culture and values. All items used the 5-point Likert scale ranging from highly disagree (1) to highly agree (5). The items of each construct were in the form of statements that were direct, simple and concise. The participants had to tick the boxes next to each question according to the extent of their agreement (scale was provided at the beginning of the questionnaire). The data obtained were analyzed with SPSS for Windows 11.5. To measure the reliability of the items, Cronbach alpha value was calculated and to obtain the maximum alpha value, factor analysis was executed. In order to test the hypotheses, the analysis of Pearson correlations and linear regression were used.

\section{Findings and Discussions}

\section{Factor Analysis}

The factor analysis revealed 7 variables with Eigen values, percentage of variance explained and cumulative percentage of variance (Table 1). Of them, 2 variables; job performance, efficiency and effectiveness represented Eigen values which were greater than 1 . These two variables captured more than $95 \%$ of the variance explained in the study. Factor analysis was carried out to eliminate the inconsistent items with low factor coefficient values to have higher alpha $(\alpha>$.7) values. By and large, the alpha value greater than 0.7 is acceptable for further analysis (George \& Mallery, 2003).

\section{Table 1}

Eigen Values and Total Variance of the Items Explained in the Study

\begin{tabular}{lccc}
\hline Variables & Eigen values & $\begin{array}{c}\text { \% of variance } \\
\text { explained }\end{array}$ & $\begin{array}{c}\text { Cumulative \% of } \\
\text { variance }\end{array}$ \\
\hline Job Performance & 5.68 & 81.27 & 81.27 \\
Efficiency \& Effectiveness & 1.00 & 14.24 & 95.51 \\
Training \& Development & .19 & 2.79 & 98.3 \\
Strategic OCV & $5.42 \mathrm{E}-02$ & .77 & 99.07 \\
Knowledge \& Skills & $2.66 \mathrm{E}-02$ & .38 & 99.46 \\
Rewards \& Promotion & $2.01 \mathrm{E}-02$ & .28 & 99.74 \\
Readiness \& Flexibility & $1.76 \mathrm{E}-02$ & .25 & 100 \\
\hline
\end{tabular}

Extraction: Principal Component Analysis

Descriptive Statistics, Reliabilities, Correlations and Regression Analysis 
Descriptive statistics, reliabilities, and coefficient values of all the variables are displayed in Table 2. The mean scores were calculated by equally weighting the mean scores of all the items. The study found the highest mean score for efficient and effectiveness as 4.31. This signifies that training could play a vital role in bringing efficiency and effectiveness of employees to the organization. The mean score of job performance was 3.92 . This indicated that job analysis was vital to improve individual performance. Similarly, the mean scores of rewards and promotion, readiness and - flexibility, knowledge and skills, strategic objectives, culture and values, training and development were reported as $3.88,3.83$, $3.83,3.83$, and 3.82 respectively implying the importance of these variables in making training as a solid investment for the organization.

Hypothesis 1 predicts that training and development will be positively related to job performance, efficiency and effectiveness of employees in the organization. The study found (Table 2) significant positive relationship of training with job performance $(\mathrm{r}=.91 * *, \mathrm{p}<.01)$, efficiency and effectiveness $\left(\mathrm{r}=.88^{* *}, \mathrm{p}<.01\right)$ in the organization. Thus hypothesis 1 is accepted. The regression results in Table 3 also supported the hypothesis with job performance $\left(\beta=.95^{*}\right.$, $\mathrm{p}<.05)$, efficiency and effectiveness $(\beta=93 . *$, $\mathrm{p}<.05)$. Hypothesis 2 predicts that strategic objective, culture and value related to training and development will be positively related to job performance, efficiency and effectiveness of employees in the organization. The research indicated significant positive relationship of strategic objective, culture and value with job performance, $(\mathrm{r}=.92 * *$, $\mathrm{p}<.01)$ efficiency and effectiveness $(\mathrm{r}=.89 * *$, $\mathrm{p}<.01)$. Thus hypothesis 2 is accepted. This is also supported by the regression analysis $\left(\beta=.95^{*} ; \beta=.93 *\right)$.

\section{Table 2}

\section{Means, Standard Deviations, Reliabilities and Correlations among Variables}

\begin{tabular}{lcccccccccc}
\hline Variables & Mean & SD & 1 & 2 & 3 & 4 & 5 & 6 & 7 \\
\hline 1. Training \& Development & 3.82 & .44 & $(.81)$ & & & & & & \\
2. Strategic OCV & 3.83 & .47 & $.97 * *$ & $(.82)$ & & & & & \\
3. Knowledge \& Skills & 3.83 & .41 & $.98^{* *}$ & .97 & $(.9)$ & & & & \\
4. Rewards \& Promotion & 3.88 & .43 & $.97 * *$ & $.98^{* *}$ & $.97 * *$ & $(.8)$ & & & \\
5.Readiness \& Flexibility & 3.83 & .73 & .05 & .05 & .07 & .06 & $(.7)$ & & \\
6. Job Performance & 3.92 & .42 & $.91^{* *}$ & $.92^{* *}$ & $.92^{* *}$ & $.94^{* *}$ & .04 & $(.8)$ & \\
7. Efficiency \& Effectiveness & 4.31 & .45 & $.88^{* *}$ & $.89^{* *}$ & $.89^{* *}$ & $.90^{* *}$ & .06 & $.94^{* *}$ & $(.81)$
\end{tabular}

$\mathrm{N}=100 ; * * \mathrm{p}<.01 ;$ all items measured in 5-point scale.

Hypothesis 3 predicts that knowledge and skills related to training and development will be positively related to job performance, efficiency and effectiveness of employees in the organization. The study reported significant positive relationship of knowledge 
and skills with job performance $(\mathrm{r}=.92 * *$, $\mathrm{p}<.01)$, efficiency and effectiveness $\left(\mathrm{r}=.89^{* * *}\right.$, $\mathrm{p}<.01)$. Thus hypothesis 3 is accepted. This is also supported by the regression analysis (KS with JP and EE as $\beta=.96^{*} ; \beta=.94 *$ respectively).

\section{Table 3}

Regression Results of Variables in the Study

\begin{tabular}{|c|c|c|c|c|c|c|c|c|}
\hline \multirow{2}{*}{ Variables } & \multicolumn{4}{|c|}{$\begin{array}{l}\text { Dependent } \\
\text { Job Performance }\end{array}$} & \multicolumn{4}{|c|}{$\begin{array}{l}\text { Dependent } \\
\text { Efficiency \& Effectiveness }\end{array}$} \\
\hline & $\beta$ & $\mathrm{T}$ & $\mathrm{F}$ & $\mathrm{AR}^{2}$ & B & $\mathrm{T}$ & $\mathrm{F}$ & $\mathrm{AR}^{2}$ \\
\hline \multicolumn{9}{|l|}{ Training \& } \\
\hline Development & $.95^{*}$ & 23 & 512 & .83 & $.93 *$ & 19 & 343 & .77 \\
\hline Strategic OCV & $.95^{*}$ & 23 & 534 & .84 & $.93 *$ & 19 & 358 & .78 \\
\hline Knowledge \& Skills & $.96^{*}$ & 23 & 537 & 84 & $.94 *$ & 19 & 359 & .78 \\
\hline Reward \& Promotion & $.98^{*}$ & 26 & 676 & .87 & $.95^{*}$ & 20 & 422 & .81 \\
\hline Readiness \& Flexibility & $-.01 *$ & .38 & .15 & .01 & $-.01 *$ & .59 & .34 & .01 \\
\hline
\end{tabular}

$* \mathrm{p}<.05$

Hypothesis 4 predicts that rewards and promotions related to training and development will be positively related to job performance, efficiency and effectiveness of employees in the organization. The research found significant positive relationship of rewards and promotion with job performance $(\mathrm{r}=.94 * *, \mathrm{p}<.01)$, efficiency and effectiveness $\left(\mathrm{r}=.90^{* *}, \mathrm{p}<.01\right)$. As such the hypothesis is accepted. This is also supported by the regression analysis (RP with JP and $\mathrm{EE}$ as $\beta=.98^{*} ; \beta=.95^{*}$ respectively). Hypothesis 5 predicts that readiness and flexibility related to training and development will be positively related to job performance, efficiency and effectiveness of employees in the organization. The study indicated no relationship of readiness and flexibility with job performance, efficiency and effectiveness. So, the hypothesis is rejected. This is also supported by the regression analysis (RF with JP and $\mathrm{EE}$ as $\beta=-.01 *$; $\beta=-.01 *$ respectively).
The research found significant positive relationship of training and development with job performance, effectiveness and efficiency of employees. Similar findings were reported by Kintana, Alonso and Olaverri (2006) as they indicated that training has positive effects on productivity $(\mathrm{r}=.04)$. In another study, Zheng, Morrison and O'Neill (2006) noted that training has positive effects on competency, turnover, and employee commitment. Martell and Carroll (1995) indicated that training has positive effects on perceived business unit performance $\left(\mathrm{r}=.15^{* *}\right)$. Employers also see a bottom-line benefit from strategicallydesigned training activities. Hatch and Dyer (2004) provide empirical evidence that the investment in firm-specific human capital (e.g. training and other interventions) significantly increases firm performance. Research in strategic human resources is beginning to link investment in human 
capital including training to broader organizational outcomes such as a firm's financial performance and shareholder value (Huselid, Jackson, \& Schuler, 1997; Pfau \& Cohen, 2003).

Regarding the second hypothesis, the study found significant positive relationship of strategic objective, culture and values of the firm with job performance, effectiveness and efficiency of employees. This finding is consistent with Nixon (1995) who suggested that training can change the organizational culture to empower employees to deal with the uncertainty, complexity, chaos, and confusion of the modern workplace. Gill (1995) recommends linking training to organizational needs and strategic goals, managing training with a system view, and evaluating training with an eye to continuous improvement-all activities traditionally associated with organizational development. In another study, Noe and Colquitt (2002) focused on features of the training environment that influence how much trainees learn during training and how much this learning results in changes in their on-the-job behaviour to make the training effective. To have maximum results out of the training, the organizational strategy, culture, and values have to be consistent with training initiatives.

The study shows positive relationship of knowledge and skills with job performance effectiveness and efficiency of employees. This can be compared to the study of Hansson (2007) where he mentioned that issues of human resource management practices, line management involvement and the opportunity to practice skills were as important as the product specifications in development skills. Moreover, Phillips (1994) reported that U.S government supervisory skills training increased Return on Investment (150\%) and had positive effects on the skills. Another survey found that 96 per cent of job applicants reported that the opportunity to learn new skills was very important when evaluating a prospective employer (Leonard, 2001). In today's global economy, the knowledge, skills and abilities necessary to maintain a competitive advantage are growing and changing (Arguinis \& Kraiger, 2009). As the nature of work changes, employees are increasingly required to develop a wide, mutable set of skills that are essential to the success of their organizations. These bundle of competencies, by and large, stem from training. Training is focused on producing permanent cognitive and behavioural changes, and on developing critical competencies for job performance. Organizations make increasingly large investments in training because it serves as a powerful tool for producing the targeted cognitive, behavioural and affective learning outcomes essential for their survival (Salas \& Stagl, 2009). Effective training can yield higher productivity, improved work quality, increased motivation and commitment, higher morale and teamwork, and fewer errors, culminating in a strong competitive advantage (Salas et al., 2006).

The research reported significant positive relationship of rewards and promotions with job performance, effectiveness and efficiency of employees. This finding his congruent with Gerhart (2000) as he stated that reward system design and reward decisions can affect business performance because they "can have a positive influence on alignment of employee interests". In another study, LeBoeuf (1985) suggested that managers secure desired results through compensation and reward philosophy that recognizes employees for the right performance. In the management literature, empirical evidence suggests the moderating role of reward systems in the strategy-performance relationship (Allen \& Kilmann, 2001). 
Rajagopalan (1997) found that different incentive methods (cash versus stock options) and different time horizons (shortterm versus long-term) related to better performance in different product-market strategy situations, and that an incorrect compensation-strategy pairing can have a nonsignificant or even negative effect on performance. In addition Markham, Harlan, and Hackett (1987) noted that "viewed from a human resources management perspective, promotion enhances human capital and deploys it more effectively, thereby improving job performance and increasing satisfaction and commitment".

The study found no relationship of readiness and flexibility with performance, effectiveness and efficiency of employees. Individuals who are less conscientious, less goal-oriented, low self-disciplined, and less persevering are less likely to perceive a link between the effort they put into training and higher performance on the job (Bohlander \& Snell, 2004). For optimum learning to take place, trainees must recognize the need for new knowledge or skills. They must have a desire to learn as training progresses. This is supported by previous research by Noe and Colquitt (2002) who contend that several trainee characteristics influence trainee motivation and, thus, training effectiveness. Employees with higher cognitive ability and basic skills are proposed to be more trainable. They also proposed that trainee beliefs and attitudes influence motivation to learn in training. Trainees who are confident in training, who see the training as relevant to their jobs or careers, and who value the outcomes of training are more motivated in training.

\section{Conclusion and Implications}

The purpose of this research was to examine whether there was a relationship between the different determinants of training and development with job performance, effectiveness and efficiency of employees in a large service conglomerate. The present research considered five determinants including training and development, strategic objective, culture and values, knowledge and skills, rewards and promotions, readiness and flexibility to know the likely effect on job performance, effectiveness and efficiency. Apart from readiness and flexibility, all these dimensions moderated significantly job performance, effectiveness and efficiency of employees in the organization. In addition, all these determinants contributed significantly to elevate the level of job performance of the employees. Although readiness and flexibility did not have any effect participants agreed that a trainee's prior knowledge, skills and ability are crucial to make the training successful. This could contribute to an individual employee becoming more effective and efficient following training in the organization. The study also surfaced cause and effect relationships between and among the variables. This was noticed in the correlation and regression analyses. The study also figured out that both trainers' competency and trainees' willingness are inevitable to make the training a success. More importantly, strategic objectives, culture and values of the organization in relation to training have to be integrated to have positive changes in the organization. This was also explored in the study.

To improve training effectiveness at the organizational level, we must do a better job of linking training outcomes to organizational and business outcomes, and do so while involving organizational decision-makers. Training and development must be a rational process. Then planning for training must be a collaborative effort, involving all levels of the organization. We need to think broadly when identifying stakeholders for training. 
By involving the workforce in traditional needs-assessment processes, employees will feel greater ownership in training, and the resulting training is more likely to match individual learning styles. Through ongoing dialogue with organizational decision- makers, training professionals can stay abreast of organizational initiatives, design training interventions that matter, and frame expectations for the types of metrics and levels of evidence that will persuade key parties that training matters. Moreover, accountability for training must be emphasized throughout the organization. Survey data suggest that organizations have and will continue to invest in training to have increased levels of performance, and to make the organization more effective and efficient than before. Research on training effectiveness suggests that training has its greatest impact when all parties in the organization share responsibility for identifying training needs, ensure that trainees have the time and opportunity to focus on training, and have the opportunity and support to apply and practice trained skills on the job.

Training is a big business with both organizations and employees having high expectations about what can be accomplished. Many conditions suggest even greater expectations concerning what training needs to accomplish in the future (Goldstein \& Gilliam, 1990). Already a significant portion of our lives is spent on education and training programmes. As noted by Howell and Cooke (1989), instead of simple procedures and predictive tasks, the demands of operating extremely sophisticated computer systems require the human operator to become responsible for inferences, diagnoses, judgments, and decision-making, often under severe time pressure. All these types of developments in automation and computer technology place even greater demands on training systems to produce a highly sophisticated work force and to make them effective and efficient than ever.

Managers will need to provide on-the-job training to integrate unskilled youth into the workforce, while at the same time working with job incumbents and other managers who may not have previously been a traditional part of the workforce. Supervisors will need to perform these at a time when jobs have become increasingly complex and, national and international competitions more intense. All of these will make training in areas such as interpersonal skills even more important in the future workplace. A related impact of training is that there is an increasing emphasis on quality for both service-oriented jobs and manufacturing-oriented jobs. This has important training implications in that more employees will need to be trained in quality techniques and processes. However, for the manager, the training implications for being able to manage such phases are dramatic. Managers will be expected to understand and manage the processes for achieving quality as well as learning to manage team efforts, which are likely to be emphasized as a way of achieving success. Evidently, training can be a positive force for both the individual and the organization. To address these expectations, clearly the training agenda for the next decade will provide quite a challenge.

The study has both theoretical and practical implications. It is interesting to note that the findings point to positive reactions toward training and development, strategic objective, culture and values, knowledge and skills and rewards and promotions to obtain vital job performance, effectiveness and efficiency of the employees. In order 
for such a relationship to occur, it seems that employees must report high levels of perceived training opportunities, which may lead to higher levels of work intrinsic motivation, which then relate to employee outcomes. These are by no means novel findings, but point to the importance of training and development. Consequently, we hope the findings from our study might guide practitioners in applied settings in improving their training efforts by permeating them more fully with theoretical knowledge and empirical findings, at the cost of normative assumptions of alleged relationships between such investments and employees' performance, their continued effectiveness and efficiency in the organization. Finally, to maximize the benefits with regard to training and development, it is essential to explore further possible interrelationships between personal and organization-related factors so that trainees will take full advantage of the training experience and performance of training programmes will be maximized.

\section{Limitations and Directions for Future Research}

Several limitations of this study are identified to help guide future research. This study was conducted using data from a single organization, which may limit the generalizability of the results to other work settings, industries or even cultural contexts. It is thus important to examine whether or not findings similar to these of the present study are found in different work samples, other work settings or cultures. The sample size was very small $(\mathrm{N}=100)$ which is almost impossible to make generalizations. Furthermore, the study employed the use of convenience sampling, which cannot be considered representative of the population. However, Wallen and Fraenkel (2001) note that in convenience sampling, "the researcher is obligated to describe the sample as thoroughly as possible with respect to the variables pertinent to the study. Sometimes it is possible to show that the sample is very similar to the intended population in certain ways. In this case, the researcher can argue that the sample is representative". Location may have posed a threat to internal validity because respondents were asked their feelings about a variety of work-related issues while at work. As such, they may not have answered truthfully or responded at all, especially if they felt their responses could affect them or their job in a negative way.

Characteristics of the data collector may also have posed a threat to internal validity. In this case the study was done by mail survey and asked the collectors to obtain the completed questionnaires from the participants. If data collection were done electronically that might lessen the threat to validity posed by the traits of the data collector. Yet companies operating in Bangladesh are not proactive and/or familiar to provide empirical data in the form of virtual questionnaires. The data in this study were gathered at one point in time, making it impossible to draw inferences of causality or rule out the possibility of reverse causality. It seems likely, however, that employee perception of training opportunities will probably be influenced by other sources than training itself, and that the content and frequency of training are most probably different for employees across organizations. Another limitation is the reliance on self-reported questionnaire data, which causes concerns about possible monomethod bias and percept-percept inflated measures. The study also could not report the likely effect of intervening variables before and after training. It is expected that future research might produce very interesting and useful findings by harnessing all the aforesaid constraints. 


\section{References}

Aaker, D.A., Kumar, V., \& Day, G. S. (2001). Marketing research. John Wiley and Sons. New York, NY.

Allen, R. S., \& Kilmann, R. H. (2001). The role of the reward system for a total quality management based strategy. Journal of Organizational Change Management, 14, 110-132.

Arguinis, H., \& Kraiger, K. (2009). Benefits of training and development for individuals and teams, organizations, and society. Annual Review of Psychology, 60, 451-474.

Arthur, W., Bennett, W., Edens, P. S., \& Bell, S. T. (2003). Effectiveness of training in organizations: A meta-analysis of design and evaluation features. Journal of Applied Psychology, 88, 234-245.

Asian Development Bank. (2007). People's Republic of Bangladesh: Preparing the skills development projects. Technical Assistance Consultant Report (Dhaka, Bangladesh).

Austin, J. T., Villanova, P. Kane, J. S., \& Bernardin, H. J. (1991). Construct validation of performance measures: Definitional issues, development and evaluation of indicators. Research in Personnel and Human Resource Management. Rowland K. M. \& Ferris, G. R. Eds.). Greenwich, CT: JAI Press.

Bach, S. (2005). Managing human resource: Personnel management in transition. Oxford: Blackwell.

Bangladesh Public Administration Training Centre. (2009). Annual Report 2009. Dhaka, Bangladesh.

Barrett, A., \& O'Connell, P. J. (2001). Does training generally work? The returns to in organization training. Industrial and Labor Relations Review, 54(3), 647-662.
Bassi, L. J., \& McMurrer, D. P. (2008). Toward a human capital measurement methodology. Advances in Developing Human Resources, 10(6), 863-881.

Benson, G. S., Finegold, D., \& Mohrman, S. A. (2004). You paid for the skills, now keep them: Tuition reimbursement and voluntary turnover. Academy of Management Journal, 47(3), 315-31.

Bohlander, G., \& Snell, S. (2004). Human resource management. South-Western: Cengage Learning.

Boselie, P., Dietz, G., \& Boon, C. (2005). Commonalities and contradictions in HRM and performance research. Human Resource Management Journal, 15(3), 67-94.

Broadberry, S., \& O’Mahony, M. (2004). Britain's productivity gap with the United States and Europe: A historical perspective. National Institute Economic Review, 189, 72-85.

Bouteiller, D., \& Cossette, M. (2007). Apprentissage, Transfert, Impact, Une Exploration des Effets de la Formation dans le Secteur du Commerce de Détail (Montréal, CA: PSRA, CIRDEP, UQAM/DEFS, HEC Montreal).

Boxall, P., \& Purcell, J. (2003). Strategy and human resource management. New York: Palgrave Macmillan.

Burns, N., \& Groves, S. (2001). The practice of nursing research, conduct, critique, \& utilization (4th ed.). Toronto, Ontario: W. B. Saunders Company.

Condrey, S. E., McCoy, C. L., \& Fleury, J. M. (2006). Compensation: Choosing and using the best system for your organization. In R. R. Sims (Ed.), Human resource management: Contemporary issues, challenges, and opportunities. Charlotte, NC: Information Age Publishing.

Drucker, P. (1999). Management challenges for the 21st century. New York: Harper Collins. 
Eisenhardt, K. M. (1989). Agency theory: An assessment and review. Academy of Management Review, 14, 57-74.

Flannery, T. P., Hofrichter, D. A., \& Platten, P. E. (1996). People performance and pay: Dynamic compensation for changing organizations. New York: Free Press.

Fleishman, E. A., \& Mumford, M. D. (1989). Individual abilities and training performance.Training and Development in Organization, Goldstein, I \& Associates (Eds.). San Franciso: JosseyBass.

Gagne, R. M. (1985). The conditions of learning and theory of instruction, New York: Holt, Rinehart \& Winston. George, D., \& Mallery, P. (2003). SPSS for Windows step by step: A simple guide and reference. 11.0 update. Boston: Allyn \& Bacon.

Gerhart, B. (2000). Compensation strategy and organizational performance. In S. L. Rynes \& B. Gerhart (Ed.), Compensation in organizations: Current research and practice (15194). San Francisco, CA: Jossey Bass.

Gill, S. J. (1995). Shifting gears for high performance.Training \& Development Journal, 49, 24-31.

Goldstein, I. (1986). Training in Organizations. Monterey, CA: Brooks/ Cole.

Goldstein, I. L., \& Gilliam,P. (1990). Training system issues in the year 2000. American Psychologist, 45, 134-143.

Hambledon Group Ltd. (2000). Corporate financial performance observed before and after investors in people recognition. In Research Report RR222. Nottingham: DfEE Publications.

Hannon, E. (2005). Prospects for the upskilling of general workers in liberal market economies. Presented at British Universities Industrial Relations Association, 7-9 July, Northumbria University.

Hansson, B. (2007). Company based determinants of training and impact of training on company performance: Results from an international HRM survey. Personnel Review, 36(2), 311331.

Hatch, N. W., \& Dyer, J. H. (2004). Human capital and learning as a source of sustainable competitive advantage. Strategic Management Journal, 25, 1155-1178.

Howell, W. C., \& Cooke, N. J. (1989). Training the human information processor: A review of cognitive model. Training in Development and Organization, Goldstein, I. L. (Ed.). San Francisco, CA: Jossey Bass.

Huselid, M. A. (1995). The impact of human resource management practices on turnover productivity, and corporate financial performance. Academy of Management Journal, 38(3), 636672.

Huselid, M. A., Jackson, S. E., \& Schuler, R. S. (1997). Technical and strategic human resource management effectiveness as determinants of firm performance. Academy of Management Journal, 40, 171-188.

Kaplan,D. M., \& Ferris, G. R.(2001). Fairness perceptions of employee promotion systems: A two-study investigation of antecedents and mediators. Journal of Applied Social Psychology, 31(6), 1204-1222.

Kasl, E., Marsick, V. J., \& Dechant, K. (1997). Team as learners: A researchbased model of team learning. Journal of Applied Behavioral Science, 33, 227-246. 
Kintana, M. L., Alonso, A. U., \& Olaverri, C. (2006). High performance work systems and firms' operational performance. International Journal of Human Resource Management 17,(1), 70-85.

Kopelman, R., Brief, A., \& Guzzo, R. (1990). The role of climate and culture in productivity. In B. Schneider (Ed.), Organizational Culture and Climate, pp. 282-318 San Francisco, CA: Jossey-Bass.

Kozlowski, S., Brown, K., Weissbein, D., Cannon-Bowers, J., \& Salas, E. (2000). A multi-level approach to training effectiveness. In K. Klein, \& S. Kozlowski (Eds.), Multilevel theory, research, and methods in organizations: Foundations, extensions, and new directions, $p p$. 157-210. San Francisco, CA: JosseyBass Publishers.

Kraiger, K., \& Ford, J. K. (2007). The expanding role of workplace training: Themes and trends influencing training research and practice. In L. L. Koppes (Ed.), Historical Perspectives in Industrial and Organizational Psychology, (pp. 281-309). Mahwah, NJ: Lawrence Erlbaum Associates).

Kraiger, K., McLinden, D., \& Casper, W. J. (2004). Collaborative planning for training impact. Human Resource Management, 43(4), 337-351.

Kurosawa, M. (2001). The extent and impact of enterprise training: The case of Kitakyushu City. Japanese Economic Review, 52(2), 224-242.

Landy, F. J. (1985). Psychology of work behavior. Homewood, IL: Dorsey Press.

Lawler, E. E. III. (2000). Rewarding excellence: Pay strategies for the new economy. San Francisco, CA: JosseyBass.
LeBoeuf, M. (1985). Getting results: The secret to motivating yourself and others. New York: Berkeley Books.

Leonard, B. (2001). Training can be a valuable job perk. HR Magazine, 2, 37.

Lewis, P. (2006). Reward management. In T. Redman \& A. Wilkinson (Eds.), Contemporary Human Resource Management (2nd Ed.). London: Financial Times/Pearson.

Markham, W. T., Harlan, S. L., \& Hackett, E. J. (1987). Promotion opportunity in organizations: Causes and consequences. In K. M. Rowland \& G. R. Ferris (Eds.), Research in personnel and human resources management. Greenwich, CT: JAI Press.

Martell, K., \& Carroll, S. J. (1995). Which executive human resource management practices for the top management team are associated with higher firm performance? Human Resource Management, 34(4), 497512.

Miah, K., \& Talukder, AKMMH. (2012). The effects of employees' perception of performance appraisal process of Readymade Garments industries in Bangladesh. An empirical study. Business Review, 7(1), 94-105.

Morin,L., \& Renaud, S. (2004). Participation in corporate university training: Its effect on individual job performance. Canadian Journal of Administrative Sciences, 21(4), 295-306.

Nixon, B. (1995). Training's role in empowerment. People Management, 9, 36-38.

Nord, W. R., Brief, A. P., Atieh, J. M., \& Doherty, E. M. (1990). Studying meaning of work: The case of work values. In Brief, A. P., \& Nord W. R. (Eds.), Meanings of occupational work, pp. 21-64. Lexington, MA: Lexington Books. 
Noe, R. A., \& Colquitt, J. A. (2002).Planning for training impact: Principals of training effectiveness. In K. Kraiger (Ed.), Creating, implementing, and maintaining effective training and development: State-of-the-art lessons for practice, pp. 53-79. San Francisco: Jossey-Bass.

Pfau, B. N., \& Cohen, S. A. (2003). Aligning human capital practices and employee behavior with shareholder value. Consulting Psychology Journal: Practice and Research, 55, 169-178.

Pfeffer, J., \& Sutton, R. I. (2006). Evidencebased management. Harvard Business Review, 84(1), 62-75.

Phillips, J. J. (1994). Measuring return on investment, (Vol.1). Alexandria, VA: American Society for Training and Development. Berkeley Books.

Porter, L. W., \& Lawler, E. E. (1968). Managerial attitudes and performance. Homewood, NJ: Richard, D. Irwin.

Purcell, J. (2000). Comptroller and auditor general report on value for money examination, department of finance training and development in the civil service. Retrieved from of Ireland. Report No: 38. Available at www. audgen.gov.ie/documents/vfmreports/ Train

Purcell, J., Kinnie, N., Hutchinson, S., Rayton, B., \& Swart, J. (2003). Understanding the people and performance link: Unlocking the black box. London, CIPD.

Rajagopalan, N. (1997). Strategic orientations, incentive plan adoptions, and firm performance: Evidence from electric utility firms. Strategic Management Journal, 18(10), 761785.

Rivera, R., \& Paradise, A. (2006). State of the industry in leading enterprises: ASTD's annual review of trends in workplace learning and performance. Alexandria, VA: American Society for Training and Development.

Rothwell, W., \& Kolb, J. (1999). Major workforce and workplace trends influencing the training and development field in the USA. International Journal of Training and Development, 3, 44-53.

Saks, A. M., \& Belcourt, M. (2006). An investigation of training activities and transfer of training in organizations. Human Resource Management, 45 (4), 629-648.

Salas, E., \& Stagl, K. C. (2009). Design training systematically and follow the science of training. In E. Locke (Ed.), Handbook of principles of organizational behavior: Indispensible knowledge for evidence-based management, (2nd ed.). pp. 59-84. Chichester: John Wiley \& Sons.

Salas, E.,Wilson, K., Priest, H., \& Guthrie, J. (2006). Design, delivery, and evaluation of training systems. In G. Salvendy (Ed.), Handbook of human factors and ergonomics, (3rd ed.). pp. 472-512. Hoboken, NJ: John Wiley \& Sons.

Scott, A. S., \& Kenneth, N. W. (1985). Performance diagnosis: Identifying the causes of poor performance. Personnel Administration, 30(4), 117-127.

Sessa,V.I.,\&London,M.(2006).Continuous learning: Individual, group, and organizational perspectives. Mahwah, NJ: Lawrence Erlbaum Associates.

Shore, L. M., Tetrick, L. E., Lynch, P., \& Barksdale, K. (2006). Social and economic exchange: Construct development and validation. Journal of Applied Social Psychology, 36(4), 837-867. 
Simone, J. (2010). Training and Development.(Niles River). Retrieved from http://managementhelp.org/ trng dev/trng_dev.htm

Smith, P. (2009). The Senate of the Fifth French Republic. Basingstoke: Palgrave Macmillan.

Smith,A., \& Dowling,P.J. (2001). Analyzing firm training: Five propositions for future research. Human Resource Development Quarterly, 12(2), 147167.

SmithP.,\& Sadler-Smith,E.(2006).Learning in organizations: Complexities and diversities. Abingdon, Routledge.

Stevens, J. (1996). Applied multivariate statistics for social sciences. Mahwah, NJ: Lawrence Erlbaum Associates.

Ulrich, D., Zenger, J., \& Smallwood, N. (1999). Results-based leadership: How leaders build the needs and measure the results. San Francisco: Jossey-Bass.

Wallen, N. E., \& Fraenkel, J. R. (2001). Educational research: A guide to the process. Mahwah, NJ: Erlbaum.

Watson, S. (2008). Conceptual model for analyzing management development in the hospitality industry: A UK perspective. International Journal of Hospitality Management, 27(3), 414-425.

Wells, S. (2001). Stepping carefully. HR Magazine, 1, 44-49

Whetten, D. A., \& Cameron, K. S. (2007). Developing management skills. NJ: Prentice Hall.

Zheng, C., Morrison, M., \& O'Neill, G. (2006). An empirical study of high performance HRM practices in Chinese SMEs. International Journal of Human Resource Management, 17(10), 1772-1803. 